\title{
RATIO OF THE DIFFICULTY CRITERION IN THE COMPETITIVE FINAL SCORE IN AEROBIC GYMNASTICS
}

\section{Mariana MEZEI ${ }^{*}$, Oroles FLORESCU ${ }^{1}$, Nicoleta LEONTE ${ }^{1}$, Ofelia POPESCU ${ }^{1}$, Elena Ștefania CHIRIAC ${ }^{2}$}

\footnotetext{
${ }^{1}$ Politehnica University, Department of Physical Education and Sports-Kinetotherapy, Bucharest, Romania

${ }^{2}$ National University of Physical Education and Sport, Faculty of Physical Education and Sport, Bucharest, Romania

*Corresponding author: mariana_apostu@yahoo.com
}

https://doi.org/10.35189/dpeskj.2021.60.2.10

\begin{abstract}
The topic of this study falls within the area of concern for technicians and specialists who correlate the performance process in aerobic gymnastics with the three technical evaluation sub-criteria. This research aims to analyse a part of a competitive routine structure by recording and evaluating difficulty elements with different values, which render the entire technical difficulty criterion imposed by the requirements of the FIG Code of Points. The weight of this evaluation criterion plays a significant role in awarding the final grade. The research was based on the video analysis of 24 exercises from the last edition of the Senior World Championships held in 2018 in Guimarães, Portugal. The exercises were studied and analysed for all athletes participating in the Mixed Pair, Trio and Group finals, taking into account the specificity of obtaining the final score for this criterion. The recordings aimed at quantifying and validating the nine possible regulatory technical elements out of a total number of 271, distributed in four difficulty groups. In quantitative terms, the comparative analysis shows a percentage of only $10.70 \%$ of the total technical elements used. The promotion of as many technical elements as possible from the Code of Points leads to a decrease in the monotony and uniformity of competition exercises, propelling this type of gymnastics towards an innovative, complex and spectacular system in obtaining great performance.
\end{abstract}

Keywords: elite sport, aerobic gymnastics, difficulty.

\section{Introduction}

Aerobic gymnastics is a competitive gymnastic branch that belongs to the International Gymnastics Federation since 1994, being performed on the basis of precise regulations.

This sport originating in traditional aerobics contains complex, varied and high-intensity movements with technical difficulty elements performed to music (Briskin et al., 2016; Aleksandraviciene et al., 2015). In addition to technical difficulty elements, competitive choreography includes acrobatic elements, elements taken from rhythmic gymnastics, sequences and dance steps inspired by different styles. The choreographic act is complemented by the seven specific steps specific to traditional aerobic gymnastics (Romanchyshyn et al., 2015). All these cumulative components form a unitary whole and finally achieve the full competitive routine, thus offering the general public a unique and original artistic moment.

According to several studies (Abalo Núñez et al., 2013; Raiola et al., 2013), elite aerobic gymnastics has its own characteristics, being performed in anaerobic lactic acid conditions for about 1'30" and involving clear, precise symmetrical and asymmetrical movements produced by traditional aerobic exercises. These movements are performed fluently, with accuracy, 
speed, finesse and great artistry, thus propelling this branch of sport among competitive sports with a high level of spectacularity.

Therefore, various specialists (Briskin et al., 2014; Pityn et al., 2013; Khimenes et al., 2016) believe that further scientific research is needed to develop new concepts and strategies for designing training programmes in this gymnastic branch. This type of competitive activity needs appropriate training performed on the basis of well-established scientific data, following methodological recommendations and taking into account the specific features of this sport (Douda et al., 2008; Abdollahipour et al., 2015).

An aerobic gymnastics routine is structured on three evaluation criteria that include complex and well-defined components with an equal ratio in the final score. The three criteria are divided as follows:

- Difficulty criterion - recording the whole routine with a focus on the technical difficulty elements; evaluation, validation and quantification of technical difficulty elements with values as well as of additional points for the connections between technical difficulty elements and assigning a value for the compulsory lift performed by gymnasts.

- Artistic criterion - recording and evaluation of the whole choreography according to the five sub-criteria of the artistic factor: construction and use of the musical piece; at least eight sequences of steps specific to traditional aerobics; general content (complex and fluent transition elements on the three levels of work); varied choreography distribution across the competition area; performance quality evaluation.

- Execution criterion - evaluation of the whole routine in terms of movement precision, shape, posture, body alignment in performing difficulty elements and choreography elements, synchronisation of gymnasts in Mixed events.

The topic of this study falls within the area of concern for technicians and specialists who correlate the performance process in aerobic gymnastics with three technical evaluation subcriteria. This research aims to analyse a part of a competitive routine structure by recording and evaluating difficulty elements as an important component of the overall performance score. Due to their high degree of risk and spectacularity, they meet the technical difficulty criterion imposed by the requirements of the FIG Code of Points.

\section{Research purpose}

The purpose of this study is to obtain objective information resulting from the recording, quantification and analysis of the technical difficulty criterion structured on the three subcriteria: technical elements, combinations of technical elements and lifts.

\section{Methodology}

\section{Participants}

Research participants were gymnasts aged 18-27 years, who represented the National Aerobic Gymnastics Team in the finals of the 2018 Senior World Championships held in Guimarães, Portugal. 


\section{Methods}

A wide range of scientific research methods were used to record and analyse the collected experimental data and thus increase their efficiency:

- literature review - identifying the decisive factors of performance capacity;

- observation method - watching video recordings to identify the difficulty elements and achieve the research purpose;

- video analysis method - chronological analysis of technical elements and assigning each one a corresponding value according to the Code of Points;

- mathematical and statistical method - statistical calculation using the Microsoft Word and Microsoft Excel computer products;

- graphical and tabular method - data sampling in accordance with the technical difficulty sub-criteria specific to competitive aerobic gymnastics.

\section{Procedure}

The research consisted in the video analysis of 24 routines performed at the 2018 Aerobic Gymnastics Senior World Championships. The routines were studied and analysed for all athletes participating in the finals of the Mixed Pair, Trio and Group events, taking into account the identical specificity in obtaining the final score for this criterion.

For each routine, all three sub-criteria within the difficulty criterion were recorded and evaluated. The number and value of each technical difficulty element, the group and family elements performed throughout the choreography were considered, counting the first nine difficulties with values between 0.30 points and 1.0 point, according to the FIG Code of Points. The analysis and evaluation of a lift performed by gymnasts with change of level and shape can receive a maximum value of 1.0 point, being another sub-criterion in giving the final score. The number of additional points given for performing a combination of two or three difficulty elements or an acrobatic element combined with one or two technical elements reaches a maximum value of 0.40 points. Since their value ranges between 0.10 and 0.20 points, they can be performed twice throughout a routine. The analysis and validation of values or additional points were made according to the requirements of the 2017-2021 FIG Code of Points (Fédération Internationale de Gymnastique, 2017) as follows:

The first sub-criterion concerns the technical difficulty elements that are recorded and evaluated by assigning each one a value, according to Table 1. 
Table 1. Distribution of technical elements with different values included in the element groups/families provided by the FIG Code of Points

\begin{tabular}{|c|c|c|c|}
\hline $\begin{array}{l}\text { Difficulty } \\
\text { group }\end{array}$ & Element families/groups & $\begin{array}{l}\text { Total number } \\
\text { of element } \\
\text { families and } \\
\text { groups }\end{array}$ & $\begin{array}{l}\text { Total number of } \\
\text { elements with values } \\
\text { between } 0.30 \text { points } \\
\text { and } 1.0 \text { point }\end{array}$ \\
\hline GROUP A & Family: Push Up (PU), Explosive PU, Explosive & 5 & 64 \\
\hline Dynamic & Support, Leg Circle, Helicopter & & \\
\hline Strength & Elements: PU, Wenson PU, A-Frame, Cut, High V, & 8 & \\
\hline Elements & Reverse Cut, Leg Circle, Flair, Helicopter & & \\
\hline GROUP B & Family: Support, V-Support, Horizontal Support & 4 & 29 \\
\hline Static Strength & Elements: Straddle Support, L-Support, V-Support, & 7 & \\
\hline Elements & High V-Support, Wenson Support, Planche & & \\
\hline GROUP C & Family: Straight Jump, Horizontal Jump, Bent & 10 & 138 \\
\hline Jumps \& & Leg(s) Jump, Pike Jump, Straddle Jump, Split Jump, & & \\
\hline Leaps & Scissors Leap, Scissors Kick, Off Axis Jump, & & \\
\hline \multirow[t]{2}{*}{ Elements } & Butterfly Jump & & \\
\hline & $\begin{array}{l}\text { Elements: Air Turn, Free Fall, Gainer, Tuck, } \\
\text { Cossack, Pike, Straddle, Frontal Split, Split, Switch, } \\
\text { Scissors Leap, Scissors Kick, Off Axis Rotation, } \\
\text { Butterfly }\end{array}$ & 14 & \\
\hline GROUP D & Family: Split, Turn, Balance Turn, Illusion, Kick & 6 & 40 \\
\hline Balance \& & Elements: Spilt, Frontal Split, Vertical Split with & 8 & \\
\hline Flexibility & Turn, Turn, Turn with Leg at Horizontal, Balance & & \\
\hline Elements & Turn, Illusion, High Leg Kicks & & \\
\hline
\end{tabular}

The second sub-criterion refers to the possibility of granting criteria and additional points for the performance of a lift with maximum score according to the technical regulation:

- Way of entering the lift (acrobatic element, jump, technical element).

- Positions with different fixed shapes containing mobility, strength and balance elements.

- Changing different levels with different shapes.

- Rotation elements performed at great speed with a high degree of fluidity and dynamism.

- Elements with rotation or turn performed in the airborne phase.

The third sub-criterion of the difficulty score is reflected in giving additional points for the performance of one or two combinations of elements with technical value or acrobatic elements without any step or change of level between them. Additional points can be given as follows:

Element + Element $=0.10$ points

Element + Acrobatic $=0.10$ points

Acrobatic + Element $=0.10$ points

Acrobatic + Element + Element $=0.20$ points

Element + Element + Element $=0.20$ points

Element + Acrobatic + Element $=0.20$ points

According to several studies on the assessment and interpretation of recorded data, observation is the initial moment of knowledge (Epuran, 2005), helping to collect data and allowing their quantification through various mathematical and statistical methods (Niculescu, 2003).

In order to achieve the research purpose, we examined the validity of the nine difficulty elements imposed by the official regulation out of the total of 271 possible technical elements. 
The motor content of this sub-criterion offers a wide variety due to the different values presented in the lists of difficulties provided by the Code of Points.

Dynamic Strength Elements, Static Strength Elements, Jumps \& Leaps Elements and Balance \& Flexibility Elements are the four difficulty groups that form the technical content. One of the compulsory requirements for obtaining the total score is to use at least three of the four groups. Each group contains several families of elements that differ from each other by their shape/position, action, kinematic characteristics, etc. These in turn include elements with various values. Only one family element can be used. In the Mixed Pair and Trio events, athletes must simultaneously perform the same element with identic shape and value. The Group event differs, offering gymnasts the possibility to perform two elements from different groups or families either simultaneously or successively. They have this option only once during the choreography.

Video analysis of the three finals that took place at the 2018 Aerobic Gymnastics World Championships allowed us to identify all the elements performed by gymnasts, from the first to the last movement, throughout two stages:

- in the first stage, we recorded in chronological order all the difficulties corresponding to each element group and family, taking into account their specific code number (e.g.: the technical element with the code B200, Straddle Planche to Lifted Wenson Back to Straddle Planche, where B: group, 200: value of the element $=1.0$ point), but also the number of additional points received according to the number of combined difficulties;

- in the second stage, we evaluated and assigned a value to the compulsory lift in any composition.

After recording and identifying the codes and values of each technical component, we distributed them into groups of elements depending on each family specific to the element performed and according to the three events scheduled for our study. The order of summary data was based on the official final result of the World Championships.

In aerobic gymnastics, the Mixed Pair event involves exploring the choreography in two, and therefore the responsibilities are equally shared throughout the choreography, requiring both athletes to show strength, flexibility, interpersonal coordination and especially empathic qualities. This event must correspond to the common denominator of the two gymnasts.

\section{Results}

Table 1 shows a large variety of elements used during the eight video analysis exercises performed in the Mixed Pair event. Among the 28 recorded elements, Group C stands out with a number of 15 elements with different codes. Analysing the highest values recorded in this final, we can find only one element with a maximum value and three elements with a value of 0.90 points. This confirms once again the difficulty encountered by the coach/specialist in discovering two gymnasts with similar potential, able to achieve a maximum score in this subcriterion. The difficulties with codes D286, A207 and C466 have the highest percentage out of the 72 presented in the table. Countries such as Italy, Romania, Russia 1, Bulgaria and China did not choose any element from Group B, which was completely missing. 
Table 2. Distribution of technical difficulty elements into the four analysed value groups in the Mixed Pair final of the Senior World Championships

\begin{tabular}{|c|c|c|c|c|c|c|c|c|c|c|c|c|c|c|c|c|c|c|c|c|c|c|c|c|c|c|c|c|c|}
\hline & A & $\mathrm{A}$ & $\mathrm{A}$ & $\mathrm{A}$ & $\mathrm{A}$ & $\bar{A}$ & $f$ & & & $\bar{B}$ & $\overline{\mathrm{C}}$ & $\bar{C}$ & $\mathrm{C}$ & $\mathrm{C}$ & $\mathrm{C}$ & $\mathrm{C}$ & $\mathrm{C}$ & $\mathrm{C}$ & $\mathrm{C}$ & $\mathrm{C}$ & $\mathrm{C}$ & $\mathrm{C}$ & $\mathrm{C}$ & $\mathrm{C}$ & $\mathrm{C}$ & $\mathrm{D}$ & $\overline{\mathrm{D}}$ & $\bar{D} \mathrm{I}$ & \\
\hline & 1 & 2 & 2 & 2 & 2 & 3 & ? & & 1 & 1 & 1 & 2 & 2 & 2 & 2 & 2 & 3 & 3 & 3 & 3 & 4 & 4 & 4 & 4 & 4 & 2 & 2 & 1 & 1 \\
\hline & 8 & 0 & 2 & 3 & 3 & 1 & & & 9 & 3 & 0 & 2 & 4 & 4 & 8 & 8 & 0 & 1 & 3 & 8 & 0 & 0 & 1 & 6 & 6 & 8 & 9 & 4 & 8 \\
\hline & 6 & 7 & 8 & 7 & 9 & 0 & & & 3 & 6 & 5 & 5 & 7 & 8 & 8 & 9 & 8 & 6 & 8 & 6 & 7 & 9 & 8 & 6 & 7 & 6 & 8 & 6 & 7 \\
\hline ITA & $\mathrm{X}$ & & $\mathrm{X}$ & & & & & & & & & $\mathrm{X}$ & & & $\mathrm{X}$ & & $\mathrm{X}$ & & & & & & $\mathrm{X}$ & $\mathrm{X}$ & & $\mathrm{X}$ & & & $\bar{X}$ \\
\hline ROU & & X & & & X & & & & & & X & X & & & & $X$ & $X$ & & & & & X & & & X & X & & & \\
\hline HUN & & X & & X & & & & & & $X$ & & X & & & X & & & & X & & X & & & X & & X & & & \\
\hline RUS 1 & & $\mathrm{X}$ & & & $\mathrm{X}$ & & & & & & & & X & & $\mathrm{X}$ & & $\mathrm{X}$ & & & $X$ & & & & $X$ & & & $X$ & & \\
\hline BUL & & X & X & & & & & & & & & & X & & $X$ & & $X$ & & & $X$ & & & & X & & X & & $X$ & \\
\hline RUS 2 & & X & & & & $r$ & & & X & & & & X & & & X & $X$ & & & $\mathrm{X}$ & & & & X & & X & & & \\
\hline KOR & & & X & X & & & & & & $X$ & & & X & & $\mathrm{X}$ & & & & X & $X$ & & & & X & & X & & & \\
\hline $\mathrm{CHN}$ & & X & & & $X$ & & & & & & & & & $X$ & & X & & X & & & & X & & & X & & & $X$ & \\
\hline Total & 1 & 6 & 3 & 2 & 3 & 1 & & & & 2 & 1 & 3 & 4 & 1 & 5 & 3 & 5 & 1 & 2 & 4 & 1 & 2 & 1 & 6 & 1 & 6 & 2 & 2 & 1 \\
\hline
\end{tabular}

In order to fulfil a realistic goal and reach a place on the podium in major international competitions, participants in the Trio event must possess exceptional "athletic" qualities and a properly acquired technique with high levels of difficulty and homogeneity built during long years of training. The confrontation with multiple options for performing this event in terms of both choosing the composition of the trio and choosing/distributing the elements that encompass the difficulty criterion throughout the choreography also confirms the statistics in Table 2 of our study. The 29 codes recorded in only eight routines analysed within a major competition, the presence of four codes belonging to Group B, the fact that over $70 \%$ of difficulties have values between 0.80 and 0.90 points of the total and the variety of elements in Group A demonstrate that this is one of the most valuable and spectacular events out of the seven official events.

The distribution of technical difficulty elements into the four analysed value groups in the Trio and Group finals of the Senior World Championships is shown in Table 3 and Table 4.

Table 3. Distribution of technical difficulty elements into the four analysed value groups in the Trio event final of the Senior World Championships

\begin{tabular}{|c|c|c|c|c|c|c|c|c|c|c|c|c|c|c|c|c|c|c|c|c|c|c|c|c|c|c|c|c|c|c|}
\hline & 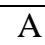 & 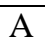 & & A & $\mathrm{A}$ & $\mathrm{A}$ & A & $\mathrm{A}$ & B & & B & B & B & $\mathrm{C}$ & $\mathrm{C}$ & $\mathrm{C}$ & $\mathrm{C}$ & $\mathrm{C}$ & $\mathrm{C}$ & $\mathrm{C}$ & $\mathrm{C}$ & $\mathrm{C}$ & $\mathrm{C}$ & $\mathrm{C}$ & $\mathrm{C}$ & $\mathrm{C}$ & $\mathrm{C}$ & $\mathrm{C}$ & & \\
\hline & 2 & 2 & 2 & 3 & 3 & 2 & 2 & 3 & 1 & & 1 & 1 & 2 & 2 & 2 & 2 & 2 & 2 & 3 & 3 & 3 & 3 & 3 & 4 & 4 & 5 & 4 & 5 & 22 & 2 \\
\hline & 0 & 0 & 1 & 1 & 8 & 3 & 3 & 6 & 3 & & 6 & 9 & 0 & 2 & 4 & 4 & 8 & 8 & 0 & 0 & 3 & 8 & 9 & 0 & 6 & 8 & 6 & 5 & 89 & 9 \\
\hline & 5 & 7 & 9 & 0 & 8 & 7 & 9 & 6 & 6 & & 8 & 8 & 0 & 5 & 7 & 8 & 8 & 9 & 7 & 8 & 8 & 6 & 7 & 9 & 6 & 7 & 7 & & & 7 \\
\hline RUS 2 & $\mathrm{X}$ & & & & $\mathrm{X}$ & & $\bar{X}$ & & & & $\bar{X}$ & & & & & & $X$ & & & $\mathrm{X}$ & & & $\mathrm{X}$ & & $\mathrm{X}$ & & & & $\mathrm{X}$ & \\
\hline CHN 1 & & & X & $X$ & & & & & & & & & X & & & & & $X$ & & & $X$ & X & & & $X$ & $X$ & & $X$ & & \\
\hline CHN 2 & & & $\mathrm{X}$ & X & & & & & & & & & $X$ & & & X & & $X$ & & & $X$ & X & & & X & $X$ & & & & \\
\hline ROU & & X & & & & & X & X & & & & & & X & & & & $X$ & & X & & & & X & & & $X$ & & X & \\
\hline HUN & & X & & & & X & & & $X$ & $\mathrm{~K}$ & & & & & X & & $X$ & & X & & & X & & & $X$ & & & & & X \\
\hline RUS 1 & & & X & $X$ & & & & X & & & & $X$ & & & & X & & $X$ & & $X$ & & & & & $X$ & & & & $\mathrm{X}$ & \\
\hline KOR & & X & & & & & & & $X$ & & & $X$ & & & $X$ & & & $X$ & & $X$ & & $X$ & & & $X$ & & & & $\mathrm{X}$ & \\
\hline VNM & & X & & & & & $\mathrm{X}$ & & $X$ & & & & & & $\mathrm{X}$ & & & $X$ & & & $X$ & X & & & $X$ & & & & $\mathrm{X}$ & \\
\hline Total & 1 & 4 & 3 & 3 & 1 & 1 & 3 & 2 & 3 & & 1 & 2 & 2 & 1 & 3 & 2 & 2 & 6 & 1 & 5 & 3 & 5 & 1 & 1 & 7 & 2 & 1 & 1 & 5 & 1 \\
\hline
\end{tabular}

Some important aspects in designing the group routines refer to the work in synchrony, the frequent changes of formations and the varied work on the three levels, which gives the five gymnasts the possibility to perform different technical difficulties. This option exists only in 
the Group event where the routines create a spectacular visual impact on the audience. In the other five events, this option is not allowed. In our analysis, we found three countries (Italy, France and Russia) that chose this option (for example, two athletes perform an element from Group B with a value of 0.60 points, and three other athletes perform an element from Group $\mathrm{C}$ with a value of 0.80 points, the Panel Jury validating the lowest difficulty used). This event has the lowest number of difficulties across the three events, being quite hard to discover five gymnasts who have the same anthropometric profile and similar technical abilities to create a connection between them and express the whole choreographic idea.

Table 4. Distribution of technical difficulty elements into the four analysed value groups in the Group event final of the Senior World Championships

\begin{tabular}{|c|c|c|c|c|c|c|c|c|c|c|c|c|c|c|c|c|c|c|c|c|c|c|c|c|c|c|}
\hline & & $\mathrm{A}$ & A & A & 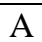 & 1 & A & B & B & $\mathrm{C}$ & C & C & C & C & $\mathrm{C}$ & C & $\mathrm{C}$ & $\mathrm{C}$ & $\mathrm{C}$ & $\mathrm{C}$ & $\mathrm{C}$ & $\mathrm{C}$ & $\mathrm{C}$ & $\mathrm{D}$ & $\mathrm{D} \mathrm{I}$ & $\overline{\mathrm{D}}$ \\
\hline & 2 & 2 & 2 & 3 & 2 & 2 & 3 & 1 & 2 & 1 & 2 & 2 & 2 & 2 & 2 & 3 & 3 & 3 & 3 & 4 & 4 & 4 & 4 & 2 & 21 & 1 \\
\hline & 0 & 1 & 2 & 1 & 3 & 3 & 6 & 3 & 0 & 0 & 2 & 4 & 4 & 8 & 8 & 0 & 0 & 3 & 8 & 0 & 1 & 6 & 6 & 8 & 92 & 4 \\
\hline & 7 & 9 & 8 & 0 & 7 & 9 & 5 & 6 & 0 & 5 & 5 & 7 & 8 & 8 & 9 & 8 & 9 & 8 & 6 & 9 & 8 & 6 & 7 & 6 & 78 & 8 \\
\hline $\mathrm{CHN}$ & $\mathrm{X}$ & & & & & X & & & & & & & X & & $\bar{X}$ & $\mathrm{X}$ & & & $\mathrm{X}$ & & & $\mathrm{X}$ & & $\mathrm{X}$ & & $\bar{X}$ \\
\hline ROU & X & & & & & $X$ & & & & $\mathrm{X}$ & $X$ & & & & X & X & & & & $X$ & & & $X$ & $X$ & & \\
\hline RUS & & $X$ & & X & & & X & & X & & & $X$ & & & X & & $X$ & & & & & $X$ & & $X$ & & \\
\hline VNM & X & & & & & $X$ & & $\mathrm{X}$ & & & & $X$ & & & X & & & $X$ & $\mathrm{X}$ & & & & $X$ & $X$ & & \\
\hline ITA & X & & $X$ & & & & X & & & & $X$ & & & X & & $X$ & & & & & $X$ & $X$ & & $X$ & & \\
\hline BUL & X & & & & $X$ & & & $\mathrm{X}$ & & & & $X$ & & X & & X & & & $\mathrm{X}$ & & & $\mathrm{X}$ & & $X$ & & \\
\hline KOR & X & & & & $X$ & & & X & & & & $X$ & & X & & $X$ & & & $X$ & & & $X$ & & $X$ & & \\
\hline FRA & X & & $X$ & & & & & $\mathrm{X}$ & & & & & X & & & $X$ & & $X$ & $\mathrm{X}$ & & & $X$ & & & X & \\
\hline Total & 7 & 1 & 2 & 1 & 2 & 3 & 2 & 4 & 1 & 1 & 2 & 4 & 1 & 3 & 4 & 6 & 1 & 1 & 5 & 1 & 1 & 6 & 2 & 7 & & 1 \\
\hline
\end{tabular}

The graph in Figure 1 shows that, out of the total number of elements performed in the 24 routines under analysis, 216 elements with different values have been identified and validated for the current study. The type and frequency of recorded codes indicate how many times an element has been repeated either in a final or overall. Technical elements with codes C466, D286, A207, C308, C386, C247, C288, C239, C289 and B136 represent $61.1 \%$ of the total number of elements. Group $\mathrm{C}$ is visibly dominant in both each event and overall exercises. Although body difficulty elements in Group B are least used, it can be seen that, in the prioritisation of difficulties, the element with the code B136 is placed in the sixth position; however, some participating countries never use elements from this group. 


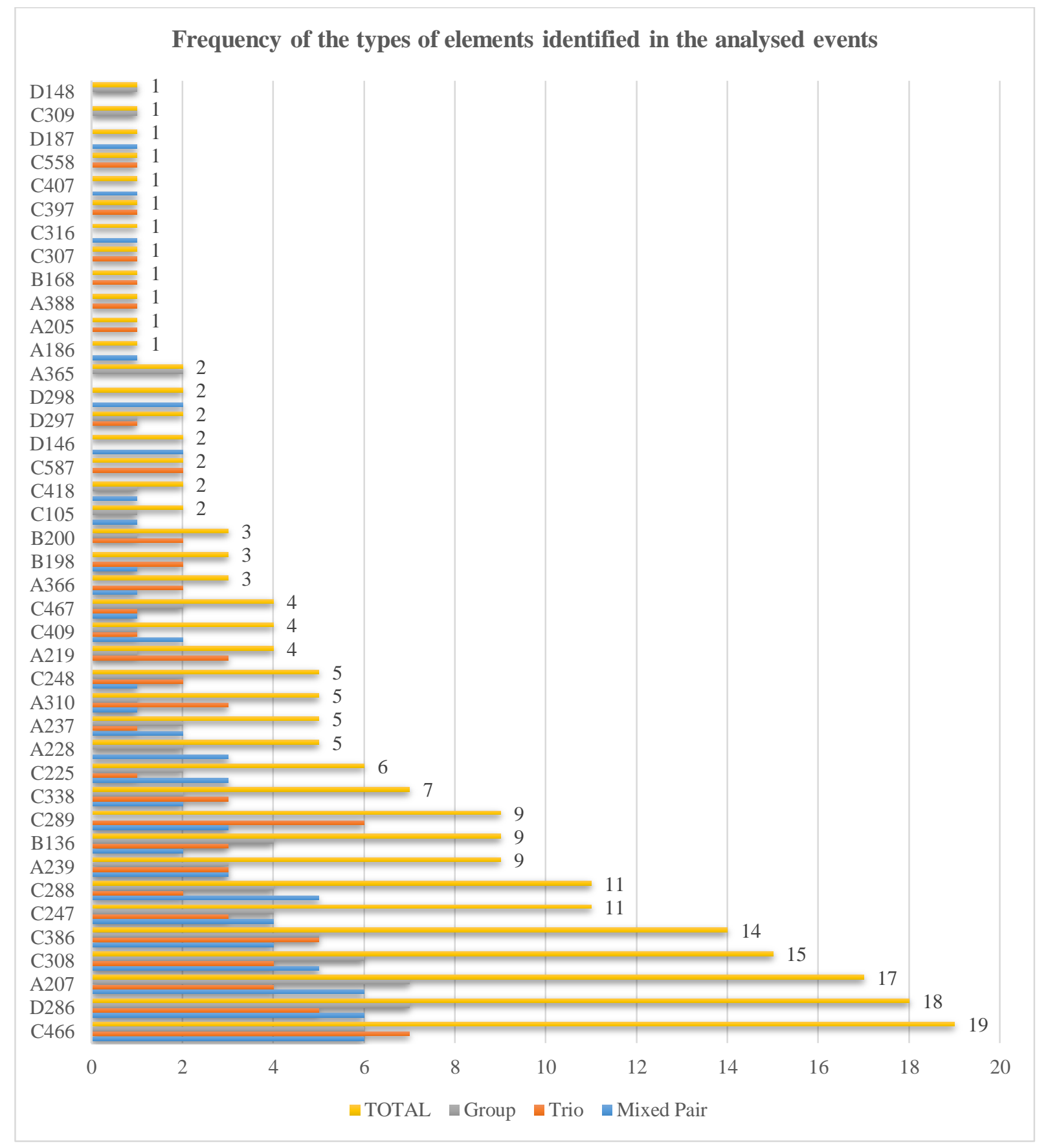

Figure 1. Distribution of technical difficulty elements into the four analysed value groups in the Mixed Pair, Trio and Group finals of the Senior World Championships

Countries with tradition and great value such as Romania, China, Russia and Korea have also left their mark on this edition of the World Championships, confirming their presence in all three analysed finals as well as in the official team and event rankings. This fact prompted us to make a mathematical and statistical analysis of the three finals by country. 


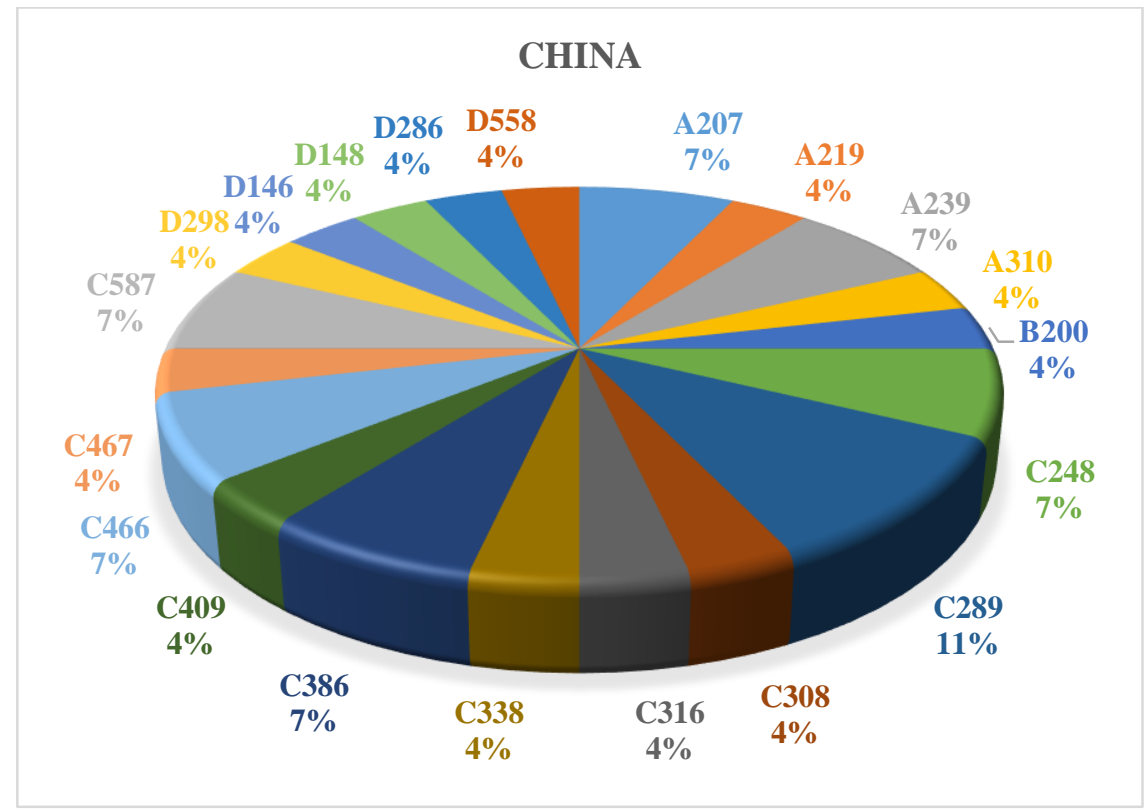

Figure 2. Percentage of technical difficulty elements used in the three events by the representative team of China

The representative team of China, the World Champion in the team rankings, uses all four body difficulty groups only in the Trio event. Figure 2 shows the dominance of Group C, "Jumps \& Leaps", in choosing the nine difficulty elements, where the element with the code C289 has a percentage of $11 \%$ of their total. The distribution of the other 20 technical elements has a homogeneous percentage comprised between $4 \%$ and $7 \%$, which confirms the variety of elements distributed on the "maps" of the three choreographies.

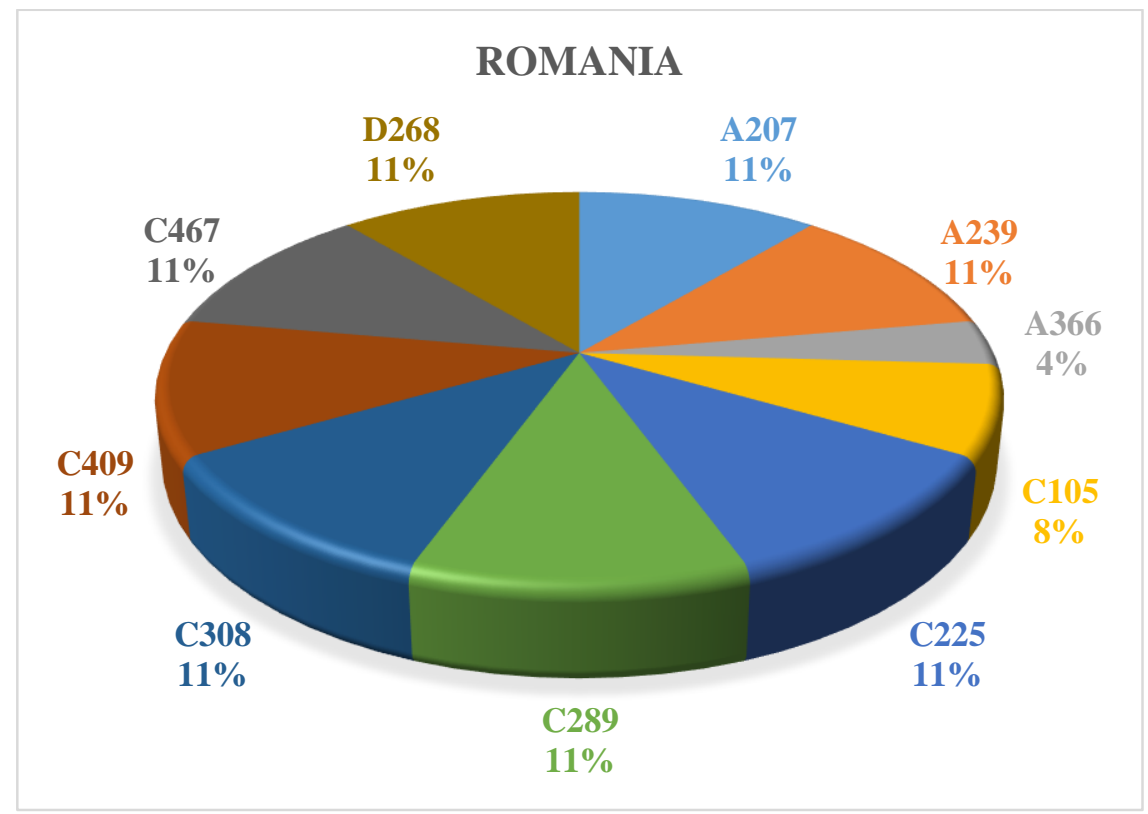

Figure 3. Percentage of technical difficulty elements used in the three analysed events by the representative team of Romania 
According to the data presented in Figure 3, Romania used a very small number of difficulties out of the 271 possible ones allowed by the FIG Code of Points in the three analysed routines. Only 10 difficulty elements were used, and Group B, "Static Strength", was completely missing. In this case, an equal percentage of $11 \%$ is revealed for eight difficulties, and for the other two, the percentage is $8 \%$ and $4 \%$, respectively.

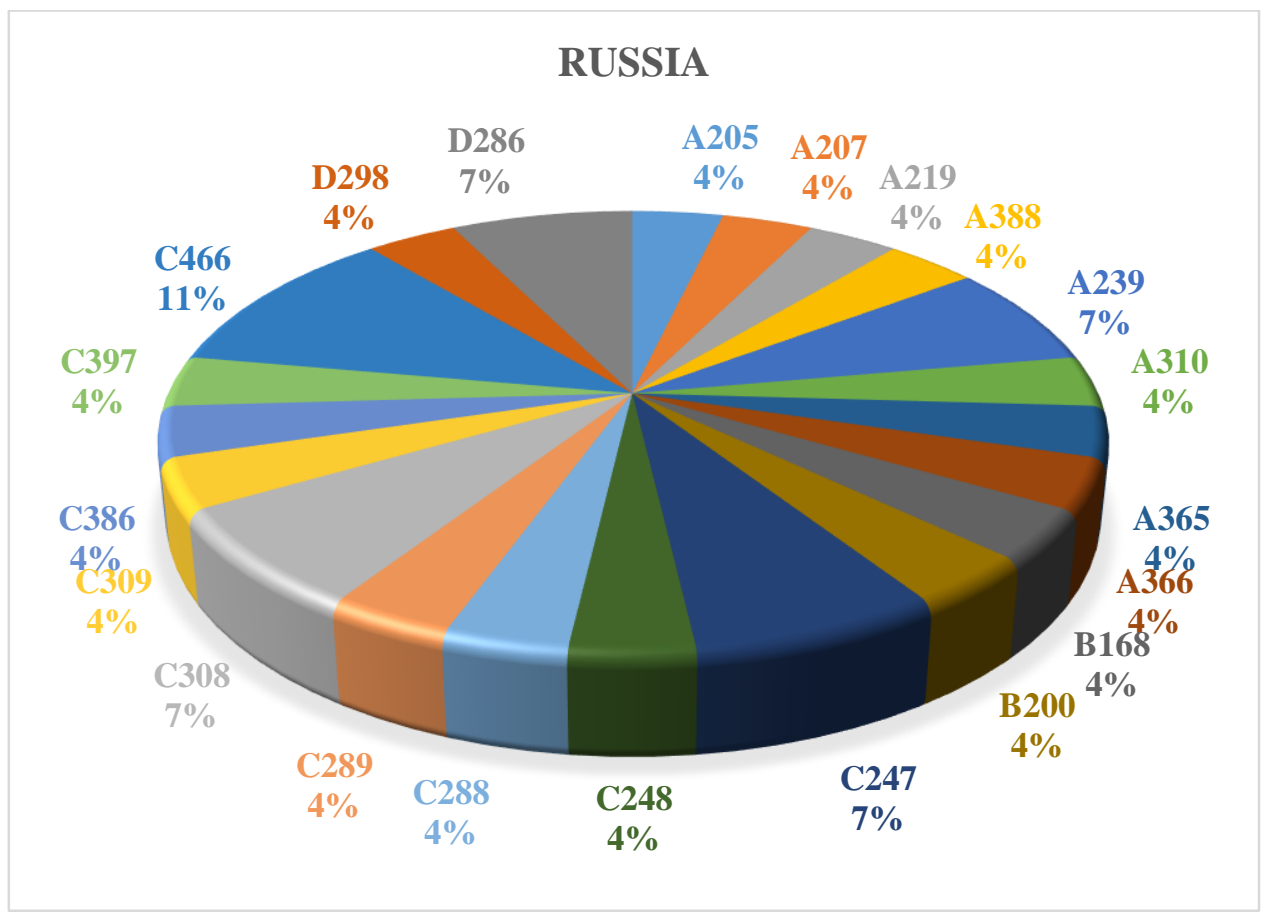

Figure 4. Percentage of technical difficulty elements used in the three events by the representative team of Russia

Figure 4 shows a multitude of codes with percentages between $4 \%$ and $7 \%$, which indicates that the representative team of Russia has the most athletes participating in this type of competition, with the greatest variety for their selection. The equal distribution of Group A, "Dynamic Strength", and Group C, "Jumps \& Leaps", with an equal number of eight elements, but also the total of 21 elements confirm the variety of the Russian school's compositions, which leads to a plus in granting the final score. In the compositions of the Group and Trio events, the four groups of elements are present. The dominant element of the three events is Scissors Leap 1/1 Turn with the code C466 and a value of 0.60 points. The presence of the Flair 1/2 Turn, 1/1 Twist Airborne to Push Up (A310) and Straddle Planche to Lifted Wenson Back to Straddle Planche (B200) elements with a maximum value of 1.0 point gives an additional chance in the fight for medals in official competitions. This type of difficulties is rarely found in the Group or Trio events due to the complexity and difficulty of being performed by several gymnasts, proving that these events can be mixed. These are strength elements with a high level of risk, which are specific to boys and therefore are often encountered in Men's Individual event. 


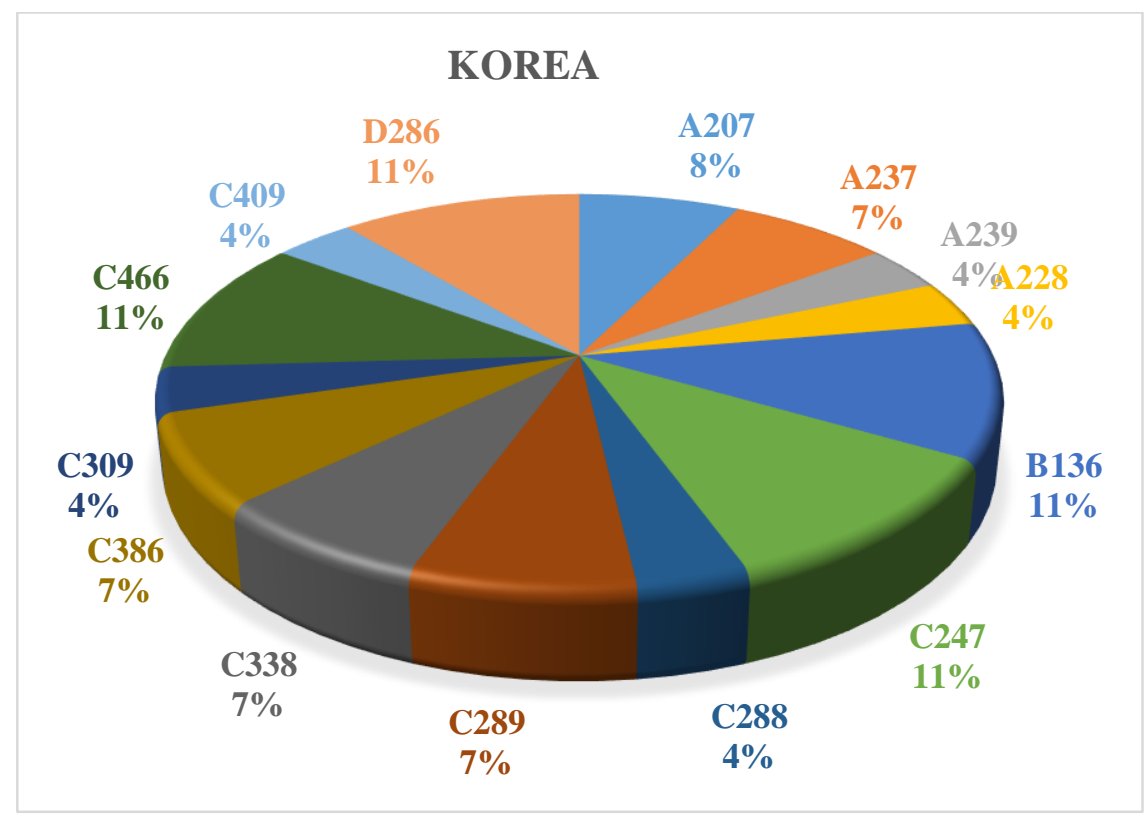

Figure 5. Percentage of technical difficulty elements used in the three events by the representative team of Korea

The representative team of Korea (Figure 5) performed 14 difficulties provided by the Code of Points, but with a distribution of the nine difficulty elements across all body groups during the three finals. The elements with codes B136, D286, C466 and C247 were found and validated in all the routines presented by this team. A percentage for variety can be seen in Group C, "Jumps \& Leaps".

The comparative analysis in quantitative terms has led to a percentage of only $10.70 \%$ of the total elements, which is confirmed by the abusive recording of the elements with codes A207, C466, C288 or D286.

The second sub-criterion of the difficulty score refers to the 0.40 points given for the combination of difficulty elements either between them or with an acrobatic element specific to artistic gymnastics. These additional points are given following the nine elements in the first technical evaluation sub-criterion.

Video analysis highlighted a generalisation of the combinations of technical elements in all the investigated events. Over $90 \%$ of combinations were made between the difficulties with codes C466-C288-A207, and a percentage of over $80 \%$, between the difficulties with codes C466-C288-C289. Despite the fact that the maximum additional value is 0.40 points in this sub-criterion, only two exercises received this additional value, being validated in the Trio event for the representative team of China 1, and the representative team of Russia 1 obtained this additional value in the Mixed Pair event. As can be seen in Table 5, over 50\% of the analysed exercises were validated for the total combinations of 0.30 points. Therefore, it has been found that the World's elite gymnasts tend to perform the same variants of combinations in all official events where they use combinations only between technical elements, and merely $2.87 \%$ use the combination of a technical element with an acrobatic element. 
Table 5. Analysis of additional points given for the difficulty criterion in the Mixed Pair event

\begin{tabular}{|c|c|c|c|}
\hline $\begin{array}{c}\text { Participating } \\
\text { country }\end{array}$ & $\begin{array}{l}\text { Combinations of } \\
\text { technical elements }\end{array}$ & $\begin{array}{l}\text { Values of the combinations of } \\
\text { technical elements }\end{array}$ & $\begin{array}{c}\text { Total additional } \\
\text { points }\end{array}$ \\
\hline ITA & $\begin{array}{l}\text { C325 + C288 + El. Ac; } \\
\text { C466 + C418 }\end{array}$ & $0.20+0.10$ & 0.30 \\
\hline ROU & $\begin{array}{l}\mathrm{C} 325+\mathrm{C} 289 \\
\mathrm{C} 308+\mathrm{A} 207\end{array}$ & $0.10+0.10$ & 0.20 \\
\hline HUN & $\begin{array}{l}\mathrm{C} 466+\mathrm{C} 288+\mathrm{A} 207 \\
\mathrm{C} 325+\mathrm{C} 338\end{array}$ & $0.20+0.10$ & 0.30 \\
\hline RUS 1 & $\begin{array}{l}\mathrm{C} 466+\mathrm{C} 298 \\
\mathrm{C} 386+\mathrm{C} 247+\mathrm{A} 207\end{array}$ & $0.10+0.20$ & 0.30 \\
\hline BUL & $\begin{array}{l}\text { C } 386+\text { C } 347 \\
\text { El. Ac + C288 + A207 }\end{array}$ & $0.10+0.20$ & 0.30 \\
\hline RUS 2 & $\begin{array}{l}\text { C466 + C386 + C288; } \\
\text { El. Ac. + C247 + A207 }\end{array}$ & $0.20+0.20$ & 0.40 \\
\hline KOR & $\begin{array}{l}\mathrm{C} 466+\mathrm{C} 288+\mathrm{A} 207 \\
\mathrm{C} 386+\mathrm{C} 247\end{array}$ & $0.20+0.10$ & 0.30 \\
\hline $\mathrm{CHN}$ & $\mathrm{C} 288+\mathrm{A} 207$ & 0.10 & 0.10 \\
\hline
\end{tabular}

The last sub-criterion that complements the final grade refers to obtaining a maximum score for the design of a lift performed by gymnasts. In the 24 routines analysed in this study, 23 lifts with a value of 1.0 point were validated, but in the Group event, the representative team of France performed a lift with a value of only 0.80 points, which influenced the final score, ranking eighth this exercise in the final of the World Championships.

We present below (Table 6) the ratio of the difficulty score obtained from the data recorded for the three cumulative sub-criteria in comparison with the other two evaluation criteria (artistic criterion and execution criterion) used in competitive aerobic gymnastics.

Table 6. Descriptive statistics for the scores obtained in the three events per evaluation criterion

\begin{tabular}{lccc}
\hline \multicolumn{4}{c}{ MIXED PAIR } \\
CRITERION & AVERAGE & STDV & CV \\
\hline D & 7.5625 & 0.199609 & 2.639458 \\
A & 8.8375 & 0.260708 & 2.950022 \\
E & 8.6375 & 0.136359 & 1.578685 \\
\hline
\end{tabular}

\begin{tabular}{|l|c|c|c|}
\hline \multicolumn{4}{|c}{ TRIO } \\
CRITERION & AVERAGE & STDV & CV \\
\hline $\mathrm{D}$ & 8.11075 & 0.580842 & 7.161379 \\
\hline $\mathrm{A}$ & 8.7625 & 0.149478 & 1.705886 \\
\hline $\mathrm{E}$ & 8.525 & 0.15 & 1.759531 \\
\hline
\end{tabular}

\begin{tabular}{lccc}
\hline & \multicolumn{3}{c}{ GROUP } \\
CRITERION & AVERAGE & STDV & CV \\
\hline D & 7.984 & 0.60525 & 7.580791 \\
A & 8.7625 & 0.140868 & 1.607622 \\
E & 8.4875 & 0.136359 & 1.606585 \\
\hline
\end{tabular}

As regards the homogeneity of the scores highlighted by the values of the coefficient of variation $(\mathrm{CV})$ for the three analysed events, we can notice the following:

- in the difficulty sub-criterion, the value of the coefficient of variation for the Mixed Pair event is only $2.63 \%$, and for the Trio and Group events, the coefficient of variation is higher (with values of $7.18 \%$ and $7.58 \%$, respectively), which indicates that the analysed group has a high level of homogeneity. 
- in the execution and artistic sub-criteria, the value of the coefficient of variation is between $1.60 \%$ and $2.95 \%$, which indicates that the analysed athletes have a very high level of homogeneity.

The maximum coefficient of deviation is $7.58 \%$, meaning that the data distribution is very small, the average being unrepresentative, and the studied sample is homogeneous because the coefficient of variation is not below the threshold of $15 \%$.

Using the coefficient of variation, we identified whether there were major differences between the competitive scores obtained by the finalists in the Mixed Pair, Trio and Group events for each evaluation sub-criterion. Thus, we noticed that the highest values were obtained in the difficulty criterion for the Trio and Group events due to the increased number of technical elements introduced in the compositions, but their values also led to a much higher score compared to the Mixed Pair event. Instead, the resulting values are very low in the execution and artistic criteria, which indicates that their level of preparation is very close.

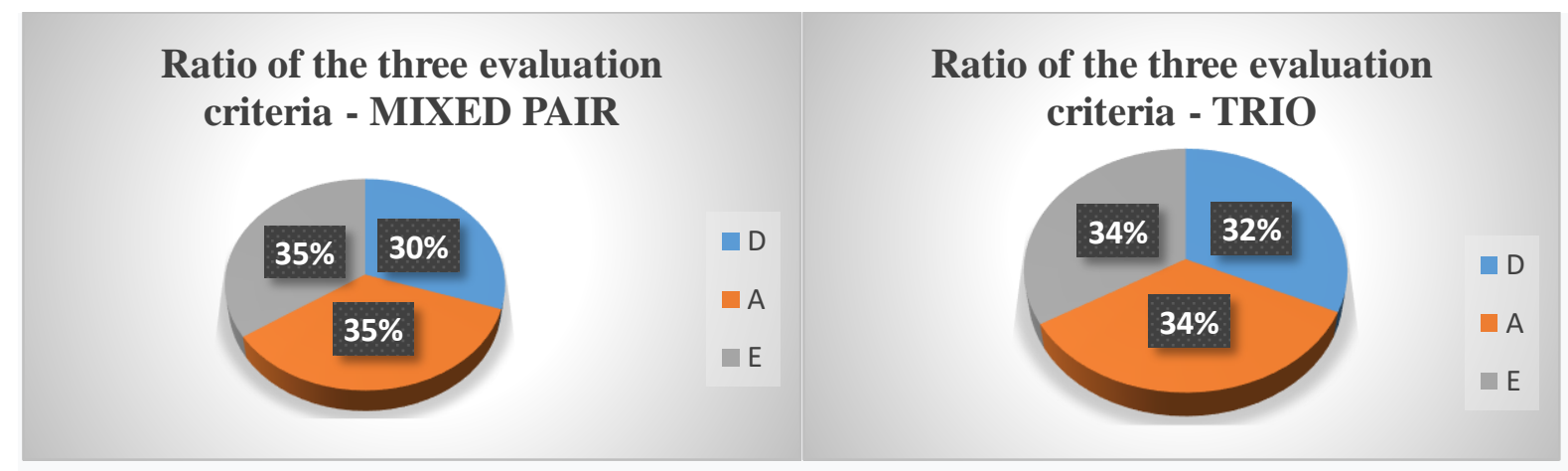

Figure 6. Ratio of the three evaluation criteria - difficulty, artistic, execution - in the Mixed Pair and Trio events

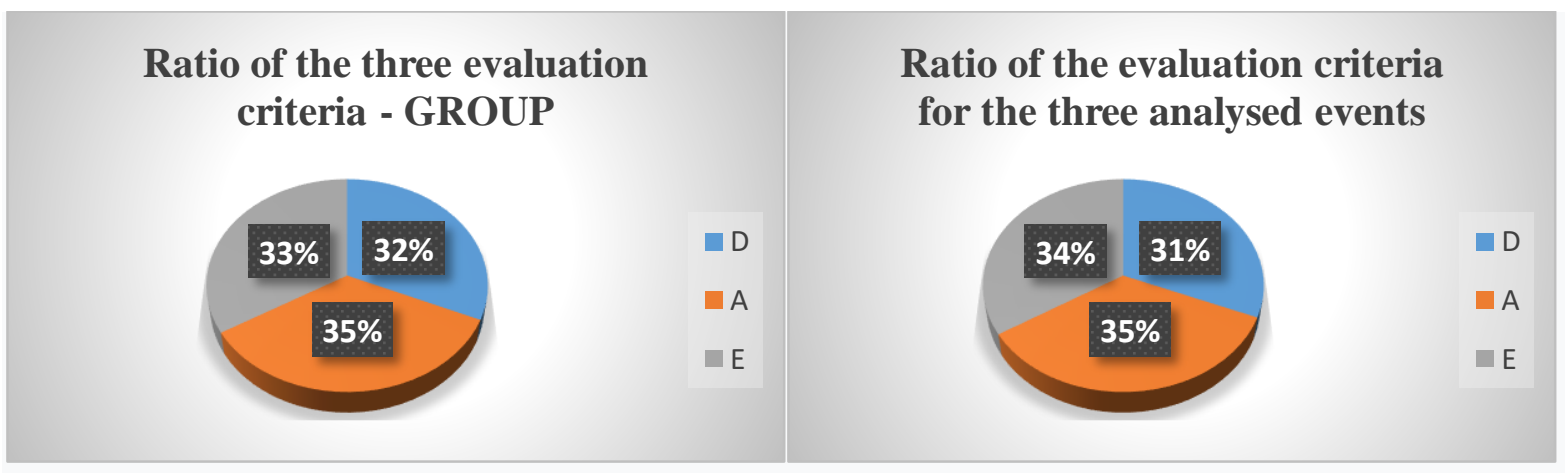

Figure 7. Ratio of the three evaluation criteria - difficulty, artistic, execution - in the Group event and overall

The data obtained from the research (Figure 6 and Figure 7) indicate that there can be no question of prioritising the three evaluation criteria in order to obtain the final score since their ratios are almost equal. The percentages with values between $30 \%$ and $35 \%$ confirm that there is a perfect correlation between them, which requires intense concentration on each one. 


\section{Discussion}

By interpreting the data from the 2018 World Championships, the study managed to outline some general trends for different countries regarding both the percentage of options for the technical elements used in designing a competitive composition and the way of obtaining an additional value to the final score. Similar research (Lijuan, 2013) reveals some of the trends analysed in this study, in the sense of acknowledging the variety of compositions and the struggle to bring new challenging difficulty elements for increasing the chances of aerobic gymnastics to become an Olympic sport.

The small number of technical elements with different values reflects the gymnasts' low technical level but also the fact that the same gymnasts perform in different events, thus configuring the same element chart, which may lead to monotony in choreographic compositions. Also, compulsory requirements for validating a combination of elements "restricts" the possibility of using as many elements as possible from different groups/families. From another point of view, evaluating and giving points for a lift is not so relevant for the difficulty criterion, considering the possibility to opt for the composition of the Trio and GroupMixed events. Commonly, a female athlete and four male athletes are used in a team, which leads very easily to achieving a maximum value for the lift.

Generally speaking, analysis of the technical content was linked by some authors (Bota \& Urzeală, 2013) to the possibility of increasing the physical and neuromuscular support of gymnasts so that they can master the difficulty elements during highly intense routines.

\section{Conclusion}

In conclusion, the small percentage used and sometimes even the lack of difficulty elements belonging to Group B are due to the execution time needed to perform them, the Executive Committee members requiring to hold the shape that defines the technical element for at least two seconds. Jumps are body elements that require dynamic execution and have the shortest but sufficient execution time to identify and perform the various shapes of the element in the maximum flight phase.

The low number of female gymnasts participating in the Trio and Group finals is also confirmed by the lack of variety of elements from Group D, "Balance \& Flexibility", which are specific to this gender.

A more varied percentage can be found in Group A, "Dynamic Strength", which is specific to active strength elements with a high degree of difficulty aimed at obtaining values that allow access to the podium.

Due to the relevance of the investigated sample and the complexity of the data obtained on the three difficulty sub-criteria, we have developed an important information base, which can be useful to the FIG Technical Committee in compiling the future Code of Points.

\section{Authors' Contributions}

All authors have equally contributed to this study and should be considered as main authors. 


\section{References}

Abalo Núñez, R., Gutiérrez-Sánchez, Á., \& Vernetta Santana, M. (2013). Analysis of incidence of injury in Spanish elite in aerobic gymnastics. Revista Brasileira de Medicina do Esporte, 19(5), 355-358. https://doi.org/10.1590/S1517-86922013000500011

Abdollahipour, R., Wulf, G., Psotta, R., \& Nieto, M. P. (2015). Performance of gymnastics skill benefits from an external focus of attention. Journal of Sports Sciences, 33(17), 18071813. https://doi.org/10.1080/02640414.2015.1012102

Aleksandraviciene, R., Zaicenkoviene, K., Stasiule, L., \& Stasiulis, A. (2015). Physiological responses and energetics of competitive group exercise in female aerobic gymnasts with different level of performance. Perceptual and Motor Skills Journal, 120(3), 787-803. https://doi.org/10.2466/29.26.pms.120v15x7

Bota, A., \& Urzeală, C. (2013). Correlative aspects regarding functional stress and neuromuscular control in high performance aerobic gymnastics - Individual events. Procedia - Social and Behavioral Sciences, 93, 2090-2094. https://doi.org/10.1016/j.sbspro.2013.10.171

Briskin, Y., Pityn, M., Antonov, S., \& Vaulin, O. (2014). Qualification differences in the structure of archery training on different stages of long-term training. Journal of Physical Education and Sport, 14(3), 426-430. http://dx.doi.org/10.7752/jpes.2014.03065

Briskin, Y., Todorova, V., Perederiy, A., \& Pityn, M. (2016). Comparative analysis of choreographic training of athletes from foreign and Ukrainian sport aerobics teams. Journal of Physical Education and Sport, 16(4), 1352-1356. DOI: 10.7752/jpes.2016.04216

Epuran, M. (2005). Metodologia cercetării activităților corporale [Research methodology of bodily activities]. FEST.

Douda, H. T., Toubekis, A. G., Avloniti, A., \& Tokmakidis, S. P. (2008). Physiological and anthropometric determinants of rhythmic gymnastics performance. International Journal of Sports Physiology and Performance, 3(1), 41-54. https://doi.org/10.1123/ijspp.3.1.41

Fédération Internationale de Gymnastique. (2017). 2017-2020 Code of Points Aerobic Gymnastics.

http://www.fig-gymnastics.com/publicdir/rules/files/en_AER\%20CoP\%202017-2020.pdf

Lijuan, G., (2013). A study on the change tendency of difficulty elements in aerobic gymnastics competitions under the new elements. Journal of Chemical and Pharmaceutical Research, 5(12), 750-756.

Khimenes, K., Lynets, M., Briskin, Y., Pityn, M., \& Galan, Y. (2016). Improvement of sportsmen physical fitness during previous basic training (based on sport orienteering material). Journal of Physical Education and Sport, 16(2), 392-396.

DOI: 10.7752/jpes.2016.02061

Niculescu, M. (2003). Metodologia cercetării științifice în educație fizică şi sport [Scientific research methodology in physical education and sport]. Bren.

Pityn, M., Briskin, Y., \& Zadorozhna, O. (2013). Features of theoretical training in combative sports. Journal of Physical Education and Sport, 13(2), 195-198.

DOI: 10.7752/jpes.2015.03082

Raiola, G., Giugno, Y., Scassilo, I., \& Di Tore, P. A. (2013). An experimental study on Aerobic Gymnastic: Performance analysis as an effective evaluation for technique and teaching of motor gestures. Journal of Human Sport and Exercise, 8(2), 297-306. http://dx.doi.org/10.4100/jhse.2012.8.Proc2.32

Romanchyshyn, O., Briskin, Y., Sydorko, O., Ostrovs'kyy, M., \& Pityn, M. (2015). Pedagogical colleges students' readiness formation for sport and recreation activity. Journal of Physical Education and Sport, 15(4), 815-822. DOI: 10.7752/jpes.2015.04125 